\title{
Article \\ Outcomes of Bone Marrow Compared to Peripheral Blood for Haploidentical Transplantation
}

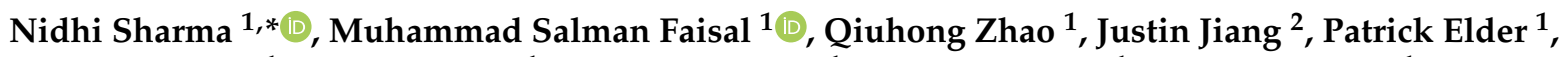 \\ Don M. Benson ${ }^{1}$, Ashley Rosko ${ }^{1}$, Maria Chaudhry ${ }^{1}$, Naresh Bumma ${ }^{1}$, Abdullah Khan ${ }^{1}$, \\ Srinivas Devarakonda ${ }^{1}$ (D), Sumithira Vasu ${ }^{1}$, Samantha Jaglowski ${ }^{1}$, Alice S. Mims ${ }^{1}$, Hannah Choe ${ }^{1}$, \\ Karilyn Larkin ${ }^{1}$, Jonathan E. Brammer ${ }^{1}$, Sarah Wall ${ }^{1}$, Nicole Grieselhuber ${ }^{1}$, Ayman Saad ${ }^{1}$, Sam Penza ${ }^{1}$, \\ Audrey M. Sigmund ${ }^{1}$ and Yvonne A. Efebera ${ }^{1}$
}

1 Division of Hematology, Department of Internal Medicine, The Ohio State University, Columbus, OH 43210, USA; Muhammad.Faisal2@osumc.edu (M.S.F.); Qiuhong.Zhao@osumc.edu (Q.Z.); Patrick.Elder@osumc.edu (P.E.); Don.Benson@osumc.edu (D.M.B.); Ashley.Rosko@osumc.edu (A.R.); Maria.Chaudhry@osumc.edu (M.C.); Naresh.Bumma@osumc.edu (N.B.); Abdullah.Khan@osumc.edu (A.K.); Srinivas.Devarakonda@osumc.edu (S.D.); Sumithira.Vasu@osumc.edu (S.V.);

Samantha.Jaglowski@osumc.edu (S.J.); Alice.Mims@osumc.edu (A.S.M.); Hannah.Choe@osumc.edu (H.C.); Karilyn.Larkin@osumc.edu (K.L.); Jonathan.Brammer@osumc.edu (J.E.B.); Sarah.Wall@osumc.edu (S.W.); Nicole.Grieselhuber@osumc.edu (N.G.); Ayman.Saad@osumc.edu (A.S.); Sam.Penza@osumc.edu (S.P.); Audrey.Sigmund@osumc.edu (A.M.S.); Yvonne.Efebera@ohiohealth.com (Y.A.E.)

2 College of Medicine, The Ohio State University, Columbus, OH 43210, USA; Justin.Jiang@osumc.edu

* Correspondence: Nidhi.Sharma@osumc.edu

check for updates

Citation: Sharma, N.; Faisal, M.S.; Zhao, Q.; Jiang, J.; Elder, P.; Benson, D.M.; Rosko, A.; Chaudhry, M.;

Bumma, N.; Khan, A.; et al.

Outcomes of Bone Marrow Compared to Peripheral Blood for Haploidentical Transplantation. J. Clin. Med. 2021, 10, 2843. https:// doi.org/10.3390/jcm10132843

Academic Editor: Franca Fagioli

Received: 18 May 2021

Accepted: 24 June 2021

Published: 27 June 2021

Publisher's Note: MDPI stays neutral with regard to jurisdictional claims in published maps and institutional affiliations.

Copyright: (c) 2021 by the authors. Licensee MDPI, Basel, Switzerland. This article is an open access article distributed under the terms and conditions of the Creative Commons Attribution (CC BY) license (https:/ creativecommons.org/licenses/by/ $4.0 /)$.

\begin{abstract}
Allogeneic hematopoietic cell transplantation (allo-HCT) from a haploidentical (haplo) donor has emerged as a suitable alternative in the absence of a matched donor. However, haplo-HCT patients have a higher risk of graft-versus-host disease (GVHD). Hence, bone marrow (BM) stem cell source and post-transplant cyclophosphamide (PTCy) have been routinely used to help mitigate this. Due to ease of collection, peripheral blood (PB) stem cells are increasingly being considered for haplo-HCT. We retrospectively analyzed 74 patients (42 BM and $32 \mathrm{~PB}$ ) who underwent haplo-HCT at Ohio State University from 2009 to 2018. Median age at transplant was 60 years (yrs) for BM and 54 yrs for PB, $(p=0.45)$. There was no difference in OS $(p=0.13)$ and NRM $(p=0.75)$ as well as PFS ( $p=0.10)$ or GRFS ( $p=0.90)$ between the groups. The BM cohort showed a 3-year OS rate of $63 \%$ (95\% confidence interval (CI): 46-76), and 3-year PFS of 49\% (95\% CI: 33-63). For the PB group, 3-year OS and PFS were 78\% (95\% CI: 59-89) and 68\% (95\% CI: 49-82), respectively. There were no differences in the incidence of acute GVHD (grade II-IV) $(p=0.31)$ and chronic GVHD ( $p=0.18$ ). Patients receiving BM had a significantly higher risk for relapse with relapse rates by 2 years at $36 \%$ (95\% CI: $22-50)$ vs. $16 \%$ (95\% CI: $6-31)$ for PB ( $p=0.03)$. The findings from this study suggest that PB is an excellent alternative to BM for haplo-HCT.
\end{abstract}

Keywords: haploidentical transplantation; peripheral blood; bone marrow; allogenic transplantation

\section{Introduction}

Allogeneic hematopoietic stem cell transplant (allo-HCT) is a potentially life-saving therapy for hematologic malignancies and other diseases. An HLA-matched sibling (MRD) is an optimal donor, but only $30 \%$ of people have such an available donor [1]. For those patients who do not have an MRD, search for matched unrelated donors (MUD) through donor registries such as the National Marrow Donor Program (NMDP) is the best option. However, the probability of finding an 8/8 MUD (HLA A, B, C, DRB1) varies significantly based on ethnicity, with probability of $75 \%$ for Caucasians but only 16-19\% for African Americans [2]. Haploidentical (haplo) donor transplant offers a great alternative donor option due to its universal availability. The majority of patients have a viable haplo donor, with $96.6 \%$ of patients having at least one haplo donor with an average of 2.5 haplo donors 
in a John Hopkins University 2006-2011 cohort [3]. The initial protocol developed for haplo-HCT involved profound T-cell depletion with myeloablative conditioning developed by the Perugia group [4]. However, there were significant limitations including longlasting immunodeficiency resulting in extraordinary non-relapse mortality (NRM) linked to infection and inadequate anti-leukemia effects resulting in early relapsed disease.

One study by Luznik et al. evaluated the outcomes of 68 patients with high-risk hematological malignancies or paroxysmal nocturnal hemoglobinuria (PNH) undergoing haplo transplant with post-transplantation cyclophosphamide (PTCy). Patients received non-myeloablative conditioning followed by a haplo transplant with bone marrow (BM) source. They were given either a single dose of PTCy on day (D)+3 (Seattle $n=28$ ) or two doses on D+3 and D+4 (Baltimore, $n=40$ ). All patients also received tacrolimus until day +180 and mycophenolate until day +35 . The incidence of graft failure was $9 / 66(13 \%)$. The incidence of acute GVHD (aGVHD) $\geq$ grade 3 was only $6 \%$ by day +200 , and the incidence of extensive chronic GVHD (cGVHD) was $5 \%$ in patients who had received two doses of PTCy. NRM at one year was 15\%. Overall survival (OS) at two years was 36\% [5]. Given that BM grafts have been shown to have a lower incidence of cGVHD [6,7], BM was utilized as the graft source both in this study [5] and in the phase 2 BMT-CTN 0603 trial [8] in an effort to mitigate GVHD incidence.

While prior studies have primarily used BM source for haplo transplants, BM harvest is not without risk and requires significant coordination of logistics and resource utilization. Thus, programs are exploring the use of peripheral blood (PB) stem cells as a source in haplo transplants. In an early clinical study using PB stem cell source, the cumulative incidence of aGVHD at one year was 53\% for grade II and $8 \%$ for grade III [9]. In a multicenter retrospective European Society for Blood and Marrow Transplantation (EBMT) analysis, aGVHD was seen more frequently in patients who received PB than BM, however, no difference was found in OS, relapse rate, or NRM [10]. A Center for International Blood and Marrow Transplant Research (CIBMTR) analysis in 2017 retrospectively reviewed 681 consecutive patients who received BM $(n=481)$ or PB $(n=190)$ with PTCy between 2009 and 2014. The risks of acute and chronic GVHD were lower in the BM group than the PB group $(p<0.001$ in both), while the relapse rate was higher in the BM group $(p=0.009)$ [11]. A recent meta-analysis of 14 studies, was also performed, which included four comparative retrospective reports and ten single-arm reports, with a total of 1759 patients who received PTCy haplo-HCT (462 patients received $\mathrm{PB}, 1297$ patients received $\mathrm{BM}$ ). The analysis showed significantly higher incidence of grade III-IV aGVHD (OR $=1.741,95 \%$ CI 1.032-2.938) and II-IV aGVHD (OR $=1.778,95 \%$ CI 1.314, 2.406) in the PB group. No significant differences were found on the incidence of relapse, 2-year OS and disease-free survival (DFS), and cGVHD between PB and BM [12].

There currently are no published prospective studies comparing BM versus $\mathrm{PB}$ stem cell source for haplo-HCT, and consequently data from retrospective analyses have helped guide the use of PB stem cell source. We therefore present our data on the effects of stem cell sources on the outcomes of haplo-HCT at our center in patients who received unmanipulated BM or PB stem cells followed by PTCy.

\section{Methods}

The bone marrow transplant registry was queried to establish a list of all patients who received allo-HCT at the Ohio State University Comprehensive Cancer Center between 2009 and 2018. A total of 74 patients were included in the final analysis. A retrospective review was conducted and all data was verified through medical chart review. Patients who received T-cell depleted grafts were excluded from the analysis. All patients received PTCy and an FK inhibitor with mycophenolate for GVHD prophylaxis.

\section{Statistical Methods}

The study's primary endpoints were OS and progression-free survival (PFS). Other study endpoints included relapse, aGVHD (grade II-IV), and cGVHD, NRM, and GVHD- 
free relapse-free survival (GRFS). All endpoints were measured from the time of transplant. Patient, disease, and transplant-related characteristics were compared between the two groups (BM versus PB) using the Mann-Whitney U test for continuous variables and chi-squared or Fisher's exact test for categorical variables. The probabilities of OS, PFS, and GRFS were calculated using the Kaplan-Meier method and compared using the log-rank test. Cumulative incidence rates for relapse, NRM, and acute and chronic GVHD were estimated and compared using Gray's test, accounting for competing risks. The competing risk for relapse was death; the competing risks for GVHD were relapse and death, while the competing risk for NRM was disease-related deaths. Univariable models were conducted using either the Cox proportional hazards model or Fine and Gray competing risk regression models to estimate the associations between transplant tissues (PB versus BM) and corresponding outcomes. Patient demographical and disease characteristic variables were evaluated for potential confounding effect in the associations between transplant tissues and outcomes. Confounders were included in final multivariable models to further estimate the adjusted effect of PB versus BM over corresponding outcomes. The significance level was set at 0.05 and all $p$-values presented were from two-sided tests. All analyses were conducted using Stata 16 (College Station, TX, USA).

\section{Results}

\subsection{Patient Characteristics}

A total of 74 patients (42 BM and $32 \mathrm{~PB}$ ) underwent haplo-HCT between 2009 to 2018 and received PTCy. The median age at transplant was 57 years (60 vs. 54 years in $\mathrm{BM}$ vs. PB groups, $p=0.45$ ). The donor's median age was 31 years (34 vs. 28 years in $\mathrm{BM}$ vs. PB group, $p=0.28)$. Forty-six patients $(62 \%)$ were male. The majority of donors were male, $74.3 \%(55 / 74)$; (81\% (34/42) in the BM group vs. $65.6 \%(21 / 32)$ in the PB group). The most common diagnosis across both groups was acute myeloid leukemia $(33.8 \%)$. Seventy-four percent of patients received fludarabine/cyclophosphamide/total body irradiation (FluCyTBI) as their conditioning regimen. The other regimens were fludarabine/busulphan/thiotepa (FluBU) (18.9\%), cyclophosphamide/total body irradiation (CyTBI) (1.4\%), fludarabine/melphalan (FluMel)(1.4\%) and fludarabine/total body irradiation (FluTBI) (4.1\%). There was no difference in conditioning regimen between the 2 groups. All patients received PTCy with tacrolimus (or sirolimus) and mycophenolate for GVHD prophylaxis.

Baseline characteristics are described in Table 1. As expected, the PB had a higher dose of CD34+ stem cells (median dose 3.7 million cells $/ \mathrm{kg}$ in the BM graft vs. 9.2 million cells $/ \mathrm{kg}$ in PB, $p<0.001)$ as well as a higher dose of CD3+ T-cells $(0.4$ million cells $/ \mathrm{kg}$ in $\mathrm{BM}$ vs. 2.3 million cells $/ \mathrm{kg}$ in $\mathrm{PB}, p<0.001$ ).

Table 1. Patient Characteristics.

\begin{tabular}{|c|c|c|c|c|c|c|c|}
\hline & \multicolumn{2}{|c|}{ All $(n=74)$} & \multicolumn{2}{|c|}{$\mathrm{BM}(n=42)$} & \multicolumn{2}{|c|}{ PB $(n=32)$} & \multirow[b]{2}{*}{$p$-Value } \\
\hline & $\mathbf{N}$ & $\%$ & $\mathbf{N}$ & $\%$ & $\mathbf{N}$ & $\%$ & \\
\hline \multirow[t]{2}{*}{ Age at $\mathrm{HCT}$, median, range } & & & & & & & 0.45 \\
\hline & 57.0 & $20-74$ & 60.0 & $21-71$ & 54.0 & $20-74$ & \\
\hline \multirow[t]{2}{*}{ Donor age, median, range } & & & & & & & 0.28 \\
\hline & 31.0 & $19-64$ & 34.0 & $19-63$ & 28.0 & $20-64$ & \\
\hline Gender, patients & & & & & & & 0.67 \\
\hline Male & 46 & 62.2 & 27 & 64.3 & 19 & 59.4 & \\
\hline Gender, donor & & & & & & & 0.13 \\
\hline Male & 55 & 74.3 & 34 & 81.0 & 21 & 65.6 & \\
\hline Recipient-donor gender & & & & & & & 0.10 \\
\hline $\mathrm{M}-\mathrm{M}$ & 35 & 47.3 & 24 & 57.1 & 11 & 34.4 & \\
\hline $\mathrm{M}-\mathrm{F}$ & 11 & 14.9 & 3 & 7.1 & 8 & 25.0 & \\
\hline $\mathrm{F}-\mathrm{M}$ & 20 & 27.0 & 10 & 23.8 & 10 & 31.3 & \\
\hline $\mathrm{F}-\mathrm{F}$ & 8 & 10.8 & 5 & 11.9 & 3 & 9.4 & \\
\hline
\end{tabular}


Table 1. Cont.

\begin{tabular}{|c|c|c|c|c|c|c|c|}
\hline & \multicolumn{2}{|c|}{ All $(n=74)$} & \multicolumn{2}{|c|}{ BM $(n=42)$} & \multicolumn{2}{|c|}{ PB $(n=32)$} & \multirow[b]{2}{*}{$p$-Value } \\
\hline & $\mathbf{N}$ & $\%$ & $\mathbf{N}$ & $\%$ & $\mathbf{N}$ & $\%$ & \\
\hline Diagnosis & & & & & & & 0.67 \\
\hline AA & 1 & 1.4 & 1 & 2.4 & 0 & 0.0 & \\
\hline ALL & 13 & 17.6 & 10 & 23.8 & 3 & 9.4 & \\
\hline AML & 25 & 33.8 & 14 & 33.3 & 11 & 34.4 & \\
\hline CML & 3 & 4.1 & 2 & 4.8 & 1 & 3.1 & \\
\hline CLL & 7 & 9.5 & 3 & 7.1 & 4 & 12.5 & \\
\hline HD & 2 & 2.7 & 1 & 2.4 & 1 & 3.1 & \\
\hline NHL & 11 & 14.9 & 5 & 11.9 & 6 & 18.8 & \\
\hline MDS & 8 & 10.8 & 5 & 11.9 & 3 & 9.4 & \\
\hline MPD & 4 & 5.4 & 1 & 2.4 & 3 & 9.4 & \\
\hline KPS & & & & & & & 0.18 \\
\hline$<90$ & 26 & 35.1 & 12 & 28.6 & 14 & 43.8 & \\
\hline$\geq 90$ & 48 & 64.9 & 30 & 71.4 & 18 & 56.3 & \\
\hline Donor type & & & & & & & 0.43 \\
\hline Matched related & 1 & 1.4 & 0 & 0.0 & 1 & 3.1 & \\
\hline Mismatch related & 73 & 98.6 & 42 & 100.0 & 31 & 96.9 & \\
\hline GVHD prophylaxis & & & & & & & 0.43 \\
\hline FK combination & 73 & 98.6 & 42 & 100.0 & 31 & 96.9 & \\
\hline Others & 1 & 1.4 & 0 & 0.0 & 1 & 3.1 & \\
\hline Conditioning & & & & & & & 0.54 \\
\hline MA & 16 & 21.6 & 8 & 19.0 & 8 & 25.0 & \\
\hline RIC & 58 & 78.4 & 34 & 81.0 & 24 & 75.0 & \\
\hline $\begin{array}{l}\text { Comorbidity index, median, } \\
\text { range }\end{array}$ & 2.5 & $0-8$ & 2 & $0-6$ & 3 & $0-8$ & \\
\hline $0-1$ & 27 & 36.5 & 18 & 42.9 & 9 & 28.1 & 0.48 \\
\hline $2-3$ & 21 & 28.4 & 12 & 28.6 & 9 & 28.1 & \\
\hline $4-5$ & 23 & 31.1 & 11 & 26.2 & 12 & 37.5 & \\
\hline $5+$ & 3 & 4.1 & 1 & 2.4 & 2 & 6.3 & \\
\hline $\begin{array}{l}\text { Remission status at } \\
\text { transplant }\end{array}$ & & & & & & & 0.83 \\
\hline $\mathrm{AP}$ & 1 & 1.5 & 1 & 2.6 & 0 & 0.0 & \\
\hline Chronic phase & 1 & 1.5 & 1 & 2.6 & 0 & 0.0 & \\
\hline CR & 47 & 72.3 & 28 & 71.8 & 19 & 73.1 & \\
\hline $\mathrm{R} / \mathrm{R}$ & 5 & 7.7 & 4 & 10.3 & 1 & 3.8 & \\
\hline PR & 9 & 13.8 & 4 & 10.3 & 5 & 19.2 & \\
\hline NA & 2 & 3.1 & 1 & 2.6 & 1 & 3.8 & \\
\hline cd34 infused, mean, SD & 5.66 & 2.9 & 3.90 & 1.7 & 7.96 & 2.6 & $<0.001$ \\
\hline cd3 infused, mean, SD & 1.28 & 1.2 & 0.38 & 0.2 & 2.45 & 1.0 & $<0.001$ \\
\hline Recipient-donor CMV & & & & & & & 0.67 \\
\hline Pos-Pos & 20 & 27.0 & 9 & 21.4 & 11 & 34.4 & \\
\hline Pos-Neg & 20 & 27.0 & 12 & 28.6 & 8 & 25.0 & \\
\hline Neg-Pos & 13 & 17.6 & 8 & 19.0 & 5 & 15.6 & \\
\hline Neg-Neg & 21 & 28.4 & 13 & 31.0 & 8 & 25.0 & \\
\hline Recipient-donor EBV & & & & & & & 0.81 \\
\hline Pos-Pos & 65 & 90.3 & 37 & 92.5 & 28 & 87.5 & \\
\hline Pos-Neg & 4 & 5.6 & 2 & 5.0 & 2 & 6.3 & \\
\hline Neg-Pos & 2 & 2.8 & 1 & 2.5 & 1 & 3.1 & \\
\hline Neg-Neg & 1 & 1.4 & 0 & 0.0 & 1 & 3.1 & \\
\hline
\end{tabular}

Abbreviations: $\mathrm{PB}$, peripheral blood; $\mathrm{BM}$, bone marrow; HCT, transplantation; SD, standard deviation; $\mathrm{AA}$, aplastic anemia; ALL, acute lymphocytic leukemia; AML, acute myeloid leukemia; MM, multiple myeloma; CML, chronic myelogenous leukemia; CLL, chronic lymphocytic leukemia; HD, Hodgkin's disease; NHL, nonHodgkins lymphoma; MDS, myelodysplastic syndrome; MPD, myeloproliferative disorder; KPS, Karnofsky score;MA, myeloablative; RIC, reduced intensity conditioning; $\mathrm{AP}$, accelerated phase; $\mathrm{CR}$, complete response; $\mathrm{R} / \mathrm{R}$, Relapsed/Refractory; PR, partial response; Pos, positive; neg, negative; GVHD, graft versus host disease; $\mathrm{CMV}$, cytomegalovirus; EBV, Epstein-Barr virus.

\subsection{Post-Transplant Outcomes}

The median time to neutrophil engraftment was 17.5 days in the BM group vs. 16 days in the PB group $(p=0.09)$, while the median time to platelet engraftment was 29 days in the BM group vs. 20 days in PB group $(p<0.001)$. Thirty-five patients $(83.3 \%)$ in 
the BM group achieved CR after transplant vs. $31(96.9 \%)$ in the PB group ( $p=0.18)$. No patients developed veno-occlusive disease (VOD) in either group. The incidences of complications, including pulmonary infection, bacteremia, viral reactivation, and fungemia within 100 days post-transplant were similar in both groups and are detailed in Table 2. There was only one graft failure observed in the PB group.

Table 2. Transplant outcomes of haploidentical donor with BM and PB.

\begin{tabular}{|c|c|c|c|c|c|c|c|}
\hline & \multicolumn{2}{|c|}{ All $(n=74)$} & \multicolumn{2}{|c|}{$\mathrm{BM}(n=42)$} & \multicolumn{2}{|c|}{ PB $(n=32)$} & \multirow[b]{2}{*}{$p$-Value } \\
\hline & $\mathbf{N}$ & $\%$ & $\mathbf{N}$ & $\%$ & $\mathbf{N}$ & $\%$ & \\
\hline $\begin{array}{l}\text { ANC engraftment days, } \\
\text { median, range }\end{array}$ & 17 & $8-31$ & 17.5 & $8-31$ & 16 & $13-31$ & 0.09 \\
\hline $\begin{array}{l}\text { Platelet engraftment days, } \\
\text { median, range }\end{array}$ & 27 & 13-159 & 29 & $19-82$ & 20 & 13-159 & $<0.001$ \\
\hline Post-transplant response & & & & & & & 0.18 \\
\hline CR & 66 & 89.2 & 35 & 83.3 & 31 & 96.9 & \\
\hline Less than CR & 6 & 8.1 & 5 & 11.9 & 1 & 3.1 & \\
\hline Progression & 2 & 2.7 & 2 & 4.8 & 0 & 0.0 & \\
\hline Pulmonary infection & & & & & & & 0.82 \\
\hline No & 61 & 82.4 & 35 & 83.3 & 26 & 81.3 & \\
\hline Yes & 13 & 17.6 & 7 & 16.7 & 6 & 18.8 & \\
\hline VOD & & & & & & & NA \\
\hline No & 74 & 100.0 & 42 & 100.0 & 32 & 100.0 & \\
\hline Bacteremia in first D+100 & & & & & & & 0.05 \\
\hline No & 46 & 70.8 & 23 & 60.5 & 23 & 85.2 & \\
\hline Yes & 19 & 29.2 & 15 & 39.5 & 4 & 14.8 & \\
\hline Viremia in first D+100 & & & & & & & 0.68 \\
\hline No & 25 & 37.3 & 15 & 39.5 & 10 & 34.5 & \\
\hline Yes & 42 & 62.7 & 23 & 60.5 & 19 & 65.5 & \\
\hline Fungemia in first D+100 & & & & & & & 0.99 \\
\hline No & 60 & 95.2 & 34 & 94.4 & 26 & 96.3 & \\
\hline Yes & 3 & 4.8 & 2 & 5.6 & 1 & 3.7 & \\
\hline Hemorrhagic cystitis & & & & & & & 0.99 \\
\hline No & 65 & 87.8 & 37 & 88.1 & 28 & 87.5 & \\
\hline Yes & 9 & 12.2 & 5 & 11.9 & 4 & 12.5 & \\
\hline Graft failure & 1 & 1.2 & 0 & 0.0 & 1 & 3.1 & 0.43 \\
\hline \multicolumn{8}{|l|}{ CMV reactivation } \\
\hline No & 38 & 51.35 & 22 & 52.38 & 16 & 50 & \\
\hline Yes & 36 & 48.75 & 20 & 47.62 & 16 & 50 & \\
\hline
\end{tabular}

Abbreviations: CR, complete response; VOD, veno-occlusive disease; D+, Day+; CMV, cytomegalovirus.

\subsection{Survival Outcomes}

The median follow up in the BM group was 3.6 years, versus 2.9 years in the PB group. There was no difference in OS ( $p=0.13)$ and NRM $(p=0.75)$ as well as PFS $(p=0.10)$ or GRFS $(p=0.90)$ between the groups (Figure 1). The median OS of the PB group was not reached (NR). It was 4.3 years in the BM group (95\% CI 2.0-NR) $(p=0.13)$. The probability of three year survival was 63\% (95\% CI 46-76\%) in the BM group vs. 78\% (95\% CI 59-89\%) in the PB group ( $p$ value $=0.16$ ). The median PFS was 2.2 years $(95 \% \mathrm{CI} 0.6-\mathrm{NR})$ in the BM group vs. NR (95\% CI 2.0-NR) in the PB group. The probability of 3-year PFS was $49 \%$ (95\% CI: $33-63 \%$ ) in the BM group vs. $68 \%(95 \%$ CI $49-82 \%)$ in the PB group ( $p$ value $=0.09)$. The incidence of NRM at one year was $12 \%$ (95\% CI $4-24 \%)$ in the BM group vs. $16 \%(95 \%$ CI 6-30\%) in the PB group (PB vs. BM HR = 1.21 (95\% CI: 0.38-3.89, $p=0.75$ ). PB graft had a reduced risk of relapse compared to $\mathrm{BM}$ graft. The incidence of relapse at one year was $26 \%(95 \%$ CI $14-40 \%)$ in the BM group vs. $9 \%$ (95\% CI 2-22\%) in the PB group (PB vs. BM $\mathrm{HR}=0.33$ (95\% CI: 0.13-0.88, $p=0.03$ ) (Figure 1). There were 27 deaths in the entire cohort and 4 of 27 were due to infection. 
A

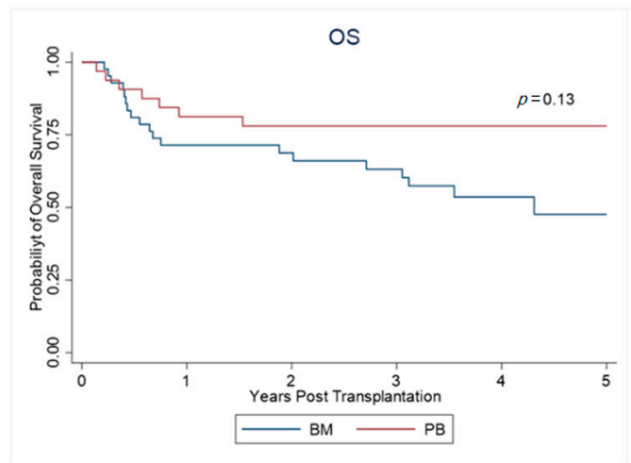

C

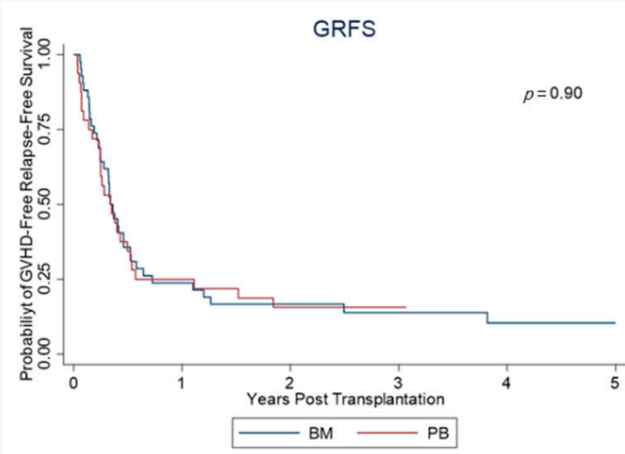

B

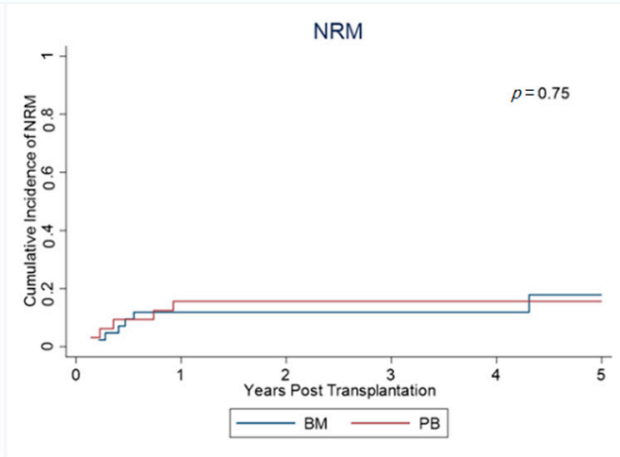

D

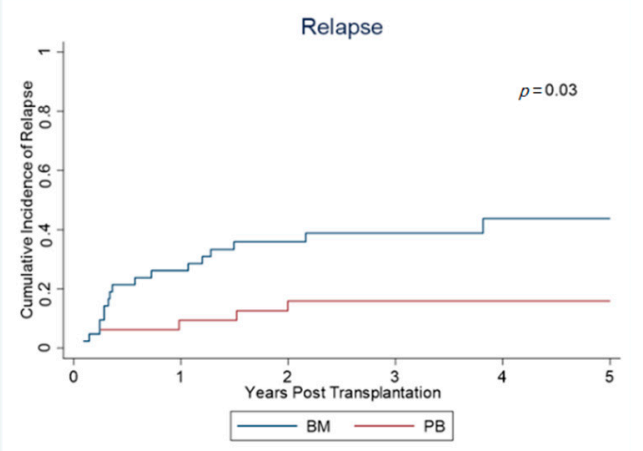

Figure 1. Comparison of survival outcomes between BM and PB grafts. (A) probability of overall survival, (B) non-relapse mortality, (C) GVHD free relapse free survival, and (D) cumulative incidence of relapse.

\subsection{Acute and Chronic GVHD}

Grade II-IV aGVHD at day 180 was 57\% (95\% CI $41-70 \%)$ in BM vs. $63 \%(95 \%$ CI $44-77 \%$ ) in PB, while grade III-IV aGVHD was $24 \%$ (95\% CI $12-37 \%$ ) vs. $25 \%$ (95\% CI $12-41 \%)$, respectively. The median survival time for GRFS was 0.3 years ( $95 \%$ CI $0.2-0.5$ ) in both groups. Table 3 describes the survival and GVHD data in further details. In multivariable analysis, PB stem cell source was associated with a decreased likelihood of relapse (HR $=0.17,95 \%$ CI $0.05-0.56, p=0.004)$, after adjusting for remission status at transplant and area of residence.

Table 3. Clinical outcomes, overall and stratified by BM and PB.

\begin{tabular}{|c|c|c|c|c|c|c|c|c|c|c|}
\hline & \multicolumn{3}{|c|}{ Overall } & \multicolumn{3}{|c|}{ BM } & \multicolumn{3}{|c|}{ PB } & \multirow[t]{2}{*}{$p$ Value } \\
\hline & \multirow[t]{2}{*}{ Rate } & \multicolumn{2}{|c|}{$95 \% \mathrm{CI}$} & \multirow[t]{2}{*}{ Rate } & \multicolumn{2}{|c|}{$95 \%$ CI } & \multirow[t]{2}{*}{ Rate } & \multicolumn{2}{|c|}{$95 \%$ CI } & \\
\hline & & & & & & & & & & \\
\hline Median OS, years & NR & 3.5 & NR & 4.3 & 2.0 & NR & NR & NR & NR & \\
\hline Year 1 & $76 \%$ & $64 \%$ & $84 \%$ & $71 \%$ & $55 \%$ & $83 \%$ & $81 \%$ & $63 \%$ & $91 \%$ & \\
\hline Year 3 & $69 \%$ & $57 \%$ & $79 \%$ & $63 \%$ & $46 \%$ & $76 \%$ & $78 \%$ & $59 \%$ & $89 \%$ & \\
\hline \multicolumn{11}{|l|}{ PFS } \\
\hline Median PFS, years & 5.8 & 1.4 & NR & 2.2 & 0.6 & NR & NR & 2.0 & NR & \\
\hline Year 1 & $68 \%$ & $56 \%$ & $77 \%$ & $62 \%$ & $46 \%$ & $75 \%$ & $75 \%$ & $56 \%$ & $87 \%$ & \\
\hline Year 3 & $57 \%$ & $45 \%$ & $68 \%$ & $49 \%$ & $33 \%$ & $63 \%$ & $68 \%$ & $49 \%$ & $82 \%$ & \\
\hline GRFS & & & & & & & & & & 0.9 \\
\hline Median GRFS, years & 0.4 & 0.3 & 0.5 & 0.3 & 0.2 & 0.5 & 0.3 & 0.2 & 0.5 & \\
\hline Year 1 & $24 \%$ & $15 \%$ & $35 \%$ & $23 \%$ & $12 \%$ & $37 \%$ & $25 \%$ & $12 \%$ & $41 \%$ & \\
\hline Year 3 & $14 \%$ & $7 \%$ & $23 \%$ & $14 \%$ & $5 \%$ & $26 \%$ & $16 \%$ & $6 \%$ & $30 \%$ & \\
\hline NRM & & & & & & & & & & 0.76 \\
\hline Year 1 & $14 \%$ & $7 \%$ & $22 \%$ & $12 \%$ & $4 \%$ & $24 \%$ & $16 \%$ & $6 \%$ & $30 \%$ & \\
\hline Year 3 & $14 \%$ & $7 \%$ & $22 \%$ & $12 \%$ & $4 \%$ & $24 \%$ & $16 \%$ & $6 \%$ & $30 \%$ & \\
\hline
\end{tabular}


Table 3. Cont.

\begin{tabular}{|c|c|c|c|c|c|c|c|c|c|c|}
\hline & \multicolumn{3}{|c|}{ Overall } & \multicolumn{3}{|c|}{ BM } & \multicolumn{3}{|c|}{ PB } & \multirow[t]{2}{*}{$p$ Value } \\
\hline & \multirow[t]{2}{*}{ Rate } & \multicolumn{2}{|c|}{$95 \%$ CI } & \multirow[t]{2}{*}{ Rate } & \multicolumn{2}{|c|}{$95 \%$ CI } & Rate & \multicolumn{2}{|c|}{$95 \%$ CI } & \\
\hline & & & & & & & & & & \\
\hline Year 1 & $19 \%$ & $11 \%$ & $29 \%$ & $26 \%$ & $14 \%$ & $40 \%$ & $9 \%$ & $2 \%$ & $22 \%$ & \\
\hline Year 2 & $27 \%$ & $18 \%$ & $38 \%$ & $36 \%$ & $22 \%$ & $50 \%$ & $16 \%$ & $6 \%$ & $31 \%$ & \\
\hline \multicolumn{11}{|l|}{ aGVHD,2-4 } \\
\hline Day 100 & $59 \%$ & $47 \%$ & $70 \%$ & $57 \%$ & $41 \%$ & $70 \%$ & $63 \%$ & $44 \%$ & $77 \%$ & 0.31 \\
\hline Day 180 & $59 \%$ & $47 \%$ & $60 \%$ & $57 \%$ & $41 \%$ & $70 \%$ & $63 \%$ & $44 \%$ & $77 \%$ & \\
\hline \multicolumn{11}{|l|}{ aGVHD, 3-4 } \\
\hline Day 100 & $24 \%$ & $15 \%$ & $35 \%$ & $24 \%$ & $12 \%$ & $37 \%$ & $25 \%$ & $12 \%$ & $41 \%$ & 0.79 \\
\hline Day 180 & $24 \%$ & $15 \%$ & $35 \%$ & $24 \%$ & $12 \%$ & $37 \%$ & $25 \%$ & $12 \%$ & $41 \%$ & \\
\hline \multirow{2}{*}{$\begin{array}{c}\text { cGVHD, } \\
\text { Extensive/Limited } \\
\text { Day } 365\end{array}$} & & & & & & & & & & 0.18 \\
\hline & $47 \%$ & $36 \%$ & $58 \%$ & $40 \%$ & $26 \%$ & $55 \%$ & $56 \%$ & $38 \%$ & $71 \%$ & \\
\hline cGVHD, Extensive & & & & & & & & & & 0.97 \\
\hline Day 365 & $38 \%$ & $27 \%$ & $49 \%$ & $38 \%$ & $24 \%$ & $52 \%$ & $38 \%$ & $21 \%$ & $54 \%$ & \\
\hline
\end{tabular}

Abbreviations: PB, peripheral blood; BM, bone marrow; CI, confidence interval; OS, overall survival; PFS, progression free survival; GVHD, graft-versus host disease; a, acute; c, chronic; GRFS, GVHD free relapse free survival; NRM, non-relapse mortality.

\section{Discussion}

In the last two decades, haplo-HCT has undergone revolutionary growth due to its potential to provide a large donor pool to almost everyone who requires an allogeneic stem cell transplant. BMT CTN trial 1101 showed haplo-HCT outperformed cord blood transplant in NRM and OS, with similar PFS, relapse incidence, and GVHD incidence. The trial utilized only BM as a graft source for patients receiving haplo-HCT [13], similar to the original Baltimore protocol developed at John Hopkins University [5]. However, multiple reports have demonstrated that $\mathrm{PB}$ is a safe alternative graft source to BM for haplo-HCT graft sources. In a single-center cohort study of 40 consecutive patients between 2012 and 2014, Cieri et al. used melphalan-based myeloablative conditioning and PB haploidentical stem cells and showed an NRM of $17 \%$, PFS of $48 \%$, and OS of $56 \%$ at one year. The incidence of grade II-IV aGVHD at day 100 was $15 \%$, and the incidence of cGVHD at one year was 20\% [14]. Another phase II trial from Northside Hospital Georgia with 30 patients receiving Flu-TBI conditioning and PB haplo transplant showed NRM of 3\%, a relapse rate of $24 \%$, OS of $78 \%$, and disease-free survival of $73 \%$ at two years. The incidence of aGVHD (grade II-IV) and cGVHD was $43 \%$ and $56 \%$, respectively [15]. Similar outcomes have been reported in other studies for PB stem cell source $[9,16]$.

Our retrospective study compares the outcomes of haplo-HCT between a PB and $\mathrm{BM}$ source. Patients in the PB group received more CD3+ and CD34+ cells than the BM, which is consistent with the collection yield of both graft sources [17]. The median time to neutrophil engraftment is similar in BM and PB source (17.5 vs. 16 days, $p=0.09)$, whereas the median time to platelet engraftment is quicker in the PB group ( 29 vs. 20 days, $p<0.001$ ). Bashey et al. showed a similar trend in their analysis with a larger patient population, detecting a significant difference between both groups (BM vs. PB) in count recovery with the median days of 17 vs. $16(p<0.001)$ in neutrophil recovery and 26 vs. $25(p<0.001)$ days in platelet recovery [11]. While we did not see a similar statistical difference in neutrophil engraftment, this was most likely due to the smaller number of patients included in our cohort. We also had only one incident of graft failure in the PB cohort, which suggests excellent engraftment with a haplo-HCT in our patient population.

Our study shows that BM and PB grafts are similar in outcomes in terms of acute and chronic GVHD, NRM, and GRFS. This is similar to what has been reported previously [18-20]. However, a large retrospective CIBMTR database analysis showed a higher incidence of grade II-IV aGVHD and CGVHD in PB graft. This finding may be due to the heterogeneity in groups with a higher number of patients receiving myeloablative doses of TBI (31\% in patients in PB group in the Bashey et al. study) [11]. Our data also shows there is a 
non-significant trend towards improved PFS and OS (49\% vs. $68 \%$ and $63 \%$ vs. $78 \%$ at 3 years, respectively), favoring PB.

Our study also demonstrates that the incidence of relapsed disease is significantly lower in PB graft than in BM graft (26\% vs. 9\% at 1 year). This effect is preserved on multivariable analysis after adjusting for remission status at transplant and area of residence $(\mathrm{HR}=0.17,95 \%$ CI 0.05-0.56, $p=0.004$; Tables 4 and 5). These results are similar to the ones reported by Bashey et al. in the large retrospective review and O'Donnell et al. [11,18]. The higher dose of CD3+ from donor graft in PB may result in a higher graft-vs-tumor effect. The use of PTCy does not seem to increase the relapse rate beyond that which is expected in a MUD transplant [21,22] and the current BMT CTN 1703 trial compares PTCy to the standard of care in non-myeloablative conditioning regimens in MUD and MRD transplants using PB stem cell source (NCT03959241).

Table 4. Univariable analysis of effect of PB versus BM graft on transplant outcomes.

\begin{tabular}{ccccc}
\hline & HR & 95\% CI & $p$-Value \\
\hline $\begin{array}{c}\text { Impact on OS } \\
\text { PB vs. BM }\end{array}$ & 0.50 & 0.21 & 1.21 & 0.125 \\
\hline $\begin{array}{l}\text { Impact on GRFS } \\
\text { PB vs. BM }\end{array}$ & 1.03 & 0.63 & 1.70 & 0.902 \\
\hline $\begin{array}{l}\text { Impact on NRM } \\
\text { PB vs. BM }\end{array}$ & 1.21 & 0.38 & 3.89 & 0.751 \\
\hline $\begin{array}{l}\text { Impact on relapse } \\
\text { PB vs. BM }\end{array}$ & 0.33 & 0.13 & 0.88 & 0.027 \\
\hline $\begin{array}{l}\text { Abbreviations: PB, peripheral blood; BM, bone marrow. } \\
\quad\end{array}$
\end{tabular}

Abbreviations: PB, peripheral blood; $\mathrm{BM}$, bone marrow.

Table 5. Multivariable analysis on risk of relapse, adjusting for confounding variables.

\begin{tabular}{ccccc}
\hline & HR & & $\mathbf{9 5 \%}$ CI & $p$ \\
\hline PB vs. BM & 0.17 & 0.05 & 0.56 & 0.004 \\
Rural & 3.75 & 1.39 & 10.08 & 0.009 \\
Remission status at transplant: & 1.17 & 0.40 & 3.43 & 0.774 \\
CR vs. all others & & & \\
\hline
\end{tabular}

Abbreviations: $\mathrm{PB}$, peripheral blood; $\mathrm{BM}$, bone marrow; $\mathrm{CR}$, complete response; HR, hazard ratio.

We are aware of limitations of our study. The retrospective design could introduce selection bias into our patient cohort. Moreover, we present a small sample size that limits the study's power, and subtle differences in outcomes could be missed. This may explain why non-significant OS and PFS are seen in the PB group compared to the BM group. Given that there currently is no published prospective study comparing BM versus PB haplo-HCT, retrospective analyses like ours have helped to guide the use of PB stem cell source.

\section{Conclusions}

Our study suggests that PB is an excellent alternative stem cell source to BM for haploHCT. While there was no difference in PFS, OS, GRFS, and NRM, a reduced relapse risk was observed with a PB graft. This is a small retrospective study, but provides encouraging results. A prospective randomized controlled trial is required to confirm these findings.

Author Contributions: Conception and design: Y.A.E. and N.S.; collection and assembly of data: A.S., J.J. and P.E.; data analysis and interpretation: Q.Z., M.S.F., N.S. and Y.A.E.; manuscript writing: N.S., M.S.F. and Y.A.E.; scientific input and critical comments: all authors. All authors have read and agreed to the published version of the manuscript.

Funding: This research received no external funding.

Institutional Review Board Statement: The study was conducted according to the guidelines of the Declaration of Helsinki, and approved by the Institutional Review Board of Ohio State University. 
Informed Consent Statement: Patient consent was waived due to the retrospective nature of the study and was approved by the institutional review board.

Data Availability Statement: This is Institutional data and raw data is not publicly available.

Conflicts of Interest: The authors declare no conflict of interest.

\section{References}

1. Ballen, K.K.; King, R.J.; Chitphakdithai, P.; Bolan, C.D., Jr.; Agura, E.; Hartzman, R.J.; Kernan, N.A. The national marrow donor program 20 years of unrelated donor hematopoietic cell transplantation. Biol. Blood Marrow Transplant. 2008, 14, 2-7. [CrossRef] [PubMed]

2. Gragert, L.; Eapen, M.; Williams, E.; Freeman, J.; Spellman, S.; Baitty, R.; Hartzman, R.; Rizzo, J.D.; Horowitz, M.; Confer, D.; et al. HLA Match Likelihoods for Hematopoietic Stem-Cell Grafts in the U.S. Registry. N. Engl. J. Med. 2014, 371, 339-348. [CrossRef]

3. McCurdy, S.R.; Luznik, L. How we perform haploidentical stem cell transplantation with posttransplant cyclophosphamide. Blood 2019, 134, 1802-1810. [CrossRef]

4. Aversa, F.; Tabilio, A.; Velardi, A.; Cunningham, I.; Terenzi, A.; Falzetti, F.; Ruggeri, L.; Barbabietola, G.; Aristei, C.; Latini, P.; et al. Treatment of High-Risk Acute Leukemia with T-Cell-Depleted Stem Cells from Related Donors with One Fully Mismatched HLA Haplotype. N. Engl. J. Med. 1998, 339, 1186-1193. [CrossRef] [PubMed]

5. Luznik, L.; O’Donnell, P.V.; Symons, H.J.; Chen, A.R.; Leffell, M.S.; Zahurak, M.; Gooley, T.A.; Piantadosi, S.; Kaup, M.; Ambinder, R.F.; et al. HLA-Haploidentical Bone Marrow Transplantation for Hematologic Malignancies Using Nonmyeloablative Conditioning and High-Dose, Posttransplantation Cyclophosphamide. Biol. Blood Marrow Transplant. 2008, 14, 641-650. [CrossRef] [PubMed]

6. Anasetti, C.; Logan, B.R.; Lee, S.J.; Waller, E.K.; Weisdorf, D.J.; Wingard, J.R.; Cutler, C.S.; Westervelt, P.; Woolfrey, A.; Couban, S.; et al. Peripheral-blood stem cells versus bone marrow from unrelated donors. N. Engl. J. Med. 2012, 367, 1487-1496. [CrossRef]

7. Lee, S.J.; Logan, B.; Westervelt, P.; Cutler, C.; Woolfrey, A.; Khan, S.P.; Waller, E.K.; Maziarz, R.T.; Wu, J.; Shaw, B.E.; et al. Comparison of Patient-Reported Outcomes in 5-Year Survivors Who Received Bone Marrow vs Peripheral Blood Unrelated Donor Transplantation: Long-term Follow-up of a Randomized Clinical Trial. JAMA Oncol. 2016, 2, 1583-1589. [CrossRef]

8. Brunstein, C.G.; Fuchs, E.J.; Carter, S.L.; Karanes, C.; Costa, L.J.; Wu, J.; Devine, S.M.; Wingard, J.R.; Aljitawi, O.S.; Cutler, C.S.; et al. Alternative donor transplantation after reduced intensity conditioning: Results of parallel phase 2 trials using partially HLA-mismatched related bone marrow or unrelated double umbilical cord blood grafts. Blood 2011, 118, 282-288. [CrossRef]

9. Raj, K.; Pagliuca, A.; Bradstock, K.; Noriega, V.; Potter, V.; Streetly, M.; McLornan, D.; Kazmi, M.; Marsh, J.; Kwan, J.; et al. Peripheral Blood Hematopoietic Stem Cells for Transplantation of Hematological Diseases from Related, Haploidentical Donors after Reduced-Intensity Conditioning. Biol. Blood Marrow Transplant. 2014, 20, 890-895. [CrossRef] [PubMed]

10. Ruggeri, A.; Labopin, M.; Bacigalupo, A.; Gülbas, Z.; Koc, Y.; Blaise, D.; Bruno, B.; Irrera, G.; Tischer, J.; Diez-Martin, J.L.; et al. Bone marrow versus mobilized peripheral blood stem cells in haploidentical transplants using posttransplantation cyclophosphamide. Cancer 2018, 124, 1428-1437. [CrossRef]

11. Bashey, A.; Zhang, M.J.; McCurdy, S.R.; St Martin, A.; Argall, T.; Anasetti, C.; Ciurea, S.O.; Fasan, O.; Gaballa, S.; Hamadani, M.; et al. Mobilized Peripheral Blood Stem Cells Versus Unstimulated Bone Marrow As a Graft Source for T-Cell-Replete Haploidentical Donor Transplantation Using Post-Transplant Cyclophosphamide. J. Clin. Oncol. Off. J. Am. Soc. Clin. Oncol. 2017, 35, 3002-3009. [CrossRef]

12. Yu, X.; Liu, L.; Xie, Z.; Dong, C.; Zhao, L.; Zhang, J.; Gu, J.; Zhu, H.H. Bone marrow versus peripheral blood as a graft source for haploidentical donor transplantation in adults using post-transplant cyclophosphamide-A systematic review and meta-analysis. Crit. Rev. Oncol. Hematol. 2019, 133, 120-128. [CrossRef] [PubMed]

13. Fuchs, E.J.; O’Donnell, P.V.; Eapen, M.; Logan, B.; Antin, J.H.; Dawson, P.; Devine, S.; Horowitz, M.M.; Horwitz, M.E.; Karanes, C.; et al. Double unrelated umbilical cord blood vs HLA-haploidentical bone marrow transplantation: The BMT CTN 1101 trial. Blood 2021, 137, 420-428. [CrossRef]

14. Cieri, N.; Greco, R.; Crucitti, L.; Morelli, M.; Giglio, F.; Levati, G.; Assanelli, A.; Carrabba, M.G.; Bellio, L.; Milani, R.; et al. Post-transplantation Cyclophosphamide and Sirolimus after Haploidentical Hematopoietic Stem Cell Transplantation Using a Treosulfan-based Myeloablative Conditioning and Peripheral Blood Stem Cells. Biol. Blood Marrow Transplant. 2015, 21, 1506-1514. [CrossRef] [PubMed]

15. Solomon, S.R.; Sizemore, C.A.; Sanacore, M.; Zhang, X.; Brown, S.; Holland, H.K.; Morris, L.E.; Bashey, A. Total Body IrradiationBased Myeloablative Haploidentical Stem Cell Transplantation Is a Safe and Effective Alternative to Unrelated Donor Transplantation in Patients Without Matched Sibling Donors. Biol. Blood Marrow Transplant. 2015, 21, 1299-1307. [CrossRef]

16. Gaballa, S.; Palmisiano, N.; Alpdogan, O.; Carabasi, M.; Filicko-O’Hara, J.; Kasner, M.; Kraft, W.K.; Leiby, B.; Martinez-Outschoorn, U.; O'Hara, W.; et al. A Two-Step Haploidentical Versus a Two-Step Matched Related Allogeneic Myeloablative Peripheral Blood Stem Cell Transplantation. Biol. Blood Marrow Transplant. 2016, 22, 141-148. [CrossRef] [PubMed]

17. Singhal, S.; Powles, R.; Kulkarni, S.; Treleaven, J.; Sirohi, B.; Millar, B.; Shepherd, V.; Saso, R.; Rowland, A.; Long, S.; et al. Comparison of marrow and blood cell yields from the same donors in a double-blind, randomized study of allogeneic marrow vs blood stem cell transplantation. Bone Marrow Transplant. 2000, 25, 501-505. [CrossRef] [PubMed] 
18. O'Donnell, P.V.; Eapen, M.; Horowitz, M.M.; Logan, B.R.; DiGilio, A.; Brunstein, C.; Fuchs, E.J.; Flowers, M.E.D.; Salit, R.; Raj, K.; et al. Comparable outcomes with marrow or peripheral blood as stem cell sources for hematopoietic cell transplantation from haploidentical donors after non-ablative conditioning: A matched-pair analysis. Bone Marrow Transplant. 2016, 51, 1599-1601. [CrossRef]

19. Castagna, L.; Crocchiolo, R.; Furst, S.; Bramanti, S.; El Cheikh, J.; Sarina, B.; Granata, A.; Mauro, E.; Faucher, C.; Mohty, B.; et al. Bone Marrow Compared with Peripheral Blood Stem Cells for Haploidentical Transplantation with a Nonmyeloablative Conditioning Regimen and Post-transplantation Cyclophosphamide. Biol. Blood Marrow Transplant. 2014, 20, 724-729. [CrossRef] [PubMed]

20. Bradstock, K.; Bilmon, I.; Kwan, J.; Blyth, E.; Micklethwaite, K.; Huang, G.; Deren, S.; Byth, K.; Gottlieb, D. Influence of Stem Cell Source on Outcomes of Allogeneic Reduced-Intensity Conditioning Therapy Transplants Using Haploidentical Related Donors. Biol. Blood Marrow Transplant. 2015, 21, 1641-1645. [CrossRef]

21. Ciurea, S.O.; Zhang, M.-J.; Bacigalupo, A.A.; Bashey, A.; Appelbaum, F.R.; Aljitawi, O.S.; Armand, P.; Antin, J.H.; Chen, J.; Devine, S.M.; et al. Haploidentical transplant with posttransplant cyclophosphamide vs matched unrelated donor transplant for acute myeloid leukemia. Blood 2015, 126, 1033-1040. [CrossRef] [PubMed]

22. Ruggeri, A.; Labopin, M.; Bacigalupo, A.; Afanasyev, B.; Cornelissen, J.J.; Elmaagacli, A.; Itälä-Remes, M.; Blaise, D.; Meijer, E.; Koc, Y.; et al. Post-transplant cyclophosphamide for graft-versus-host disease prophylaxis in HLA matched sibling or matched unrelated donor transplant for patients with acute leukemia, on behalf of ALWP-EBMT. J. Hematol. Oncol. 2018, 11, 40. [CrossRef] [PubMed] 